\author{
Shamly Austin \\ Srinivas Murthy \\ Hannah Wunsch \\ Neill K. J. Adhikari \\ Veena Karir \\ Kathryn Rowan \\ Shevin T. Jacob \\ Jorge Salluh \\ Fernando A. Bozza \\ Bin Du \\ Youzhong An \\ Bruce Lee \\ Felicia Wu \\ Yen-Lan Nguyen \\ Chris Oppong \\ Ramesh Venkataraman \\ Vimalraj Velayutham \\ Carmelo Dueñas \\ Derek C. Angus \\ On behalf of the International Forum \\ of Acute Care Trialists
}

Received: 7 August 2013

Accepted: 21 November 2013

Published online: 13 December 2013

(C) The Author(s) 2013. This article is published with open access at

Springerlink.com

Take-home message: The world is increasingly urbanized. Acute care services are a key part of urban infrastructure, yet there are little data on their distribution.

Across 7 cities of diverse economic background, we found up to 100 -fold variation in the supply of acute care services, such as hospital beds, ICU beds, and ambulances. Although variation in GDP was correlated with some acute care services, it did not explain the huge variation in ICU supply. Urban governments appeared to have limited knowledge of their acute care services, which raises concern regarding their ability to plan for future population growth.

S. Austin · D. C. Angus (『)

Department of Critical Care Medicine, The Clinical Research, Investigation, and Systems Modeling of Acute Illness (CRISMA) Center, University of Pittsburgh, 3550 Terrace Street, 614 Scaife Hall, Pittsburgh, PA 15261, USA

e-mail: angusdc@upmc.edu

Tel.: +1-412-6476965

Fax: +1-412-6475258

\section{Access to urban acute care services in high- vs. middle-income countries: an analysis of seven cities}

S. Murthy

Division of Critical Care,

BC Children's Hospital, University

of British Columbia, Vancouver,

BC, Canada

H. Wunsch

Department of Anesthesiology,

Columbia University,

New York, USA

H. Wunsch

Department of Epidemiology,

Columbia University, New York, USA

N. K. J. Adhikari

Department of Critical Care Medicine,

Sunnybrook Health Sciences

Centre and University of Toronto,

Toronto, Canada

V. Karir

Department of Medicine, University

of Pittsburgh, Pittsburgh, USA

K. Rowan

Intensive Care National Audit and Research

Centre, London, UK

S. T. Jacob

Division of Allergy and Infectious Diseases, Department of Medicine, International Respiratory and Severe Illness Center (INTERSECT), University of Washington, Seattle, USA
J. Salluh

D'OR Institute for Research

and Education, Rio de Janeiro,

Brazil

F. A. Bozza

Oswaldo Cruz Foundation,

Rio de Janeiro,

Brazil

B. Du

Peking Union Medical College Hospital,

Beijing, China

Y. An

Peking University People's Hospital,

Beijing, China

B. Lee

Public Health Computational and Operations Research (PHICOR) Group, Johns Hopkins Bloomberg School of Public Health, Baltimore, USA

F. Wu

Department of Food Science and Human Nutrition, Michigan State University, East Lansing, USA

\section{Y.-L. Nguyen}

Surgical ICU, Cochin Academic Hospital, Assistance Publique des Hôpitaux de Paris, Paris Descartes University, Paris, France 
Y.-L. Nguyen

Unités INSERM U738, U707, Pierre and

Marie Curie University, Paris, France

C. Oppong

Department of Emergency Medicine,

Komfo Anokye Teaching Hospital, Kumasi, Ghana

R. Venkataraman

Apollo Hospitals, Chennai, India

V. Velayutham

Stanley Medical College Hospital, Chennai, India

C. Dueñas

Intensive Care Gestion Salud, Universidad

de Cartagena, Cartagena, Colombia

C. Dueñas

Intensive Care, Hospital Santa Cruz de

Bocagrande, Cartagena, Colombia

C. Dueñas

Instituto de Simulación Médica,

Bogota, Colombia
Abstract Purpose: Cities are expanding rapidly in middle-income countries, but their supply of acute care services is unknown. We measured acute care services supply in seven cities of diverse economic background. Methods: In a crosssectional study, we compared cities from two high-income (Boston, USA and Paris, France), three upper-middle-income (Bogota, Colombia;

Recife, Brazil; and Liaocheng,

China), and two lower-middleincome (Chennai, India and Kumasi, Ghana) countries. We collected standardized data on hospital beds, intensive care unit beds, and ambulances. Where possible, information was collected from local authorities. We expressed results per population (from United Nations) and per acute illness deaths (from Global Burden of Disease project). Results: Supply of hospital beds where intravenous fluids could be delivered varied fourfold from 72.4/100,000 population in Kumasi to 241.5/100,000 in Boston. Intensive care unit (ICU) bed supply varied more than 45 -fold from 0.4 /
100,000 population in Kumasi to $18.8 / 100,000$ in Boston. Ambulance supply varied more than 70 -fold. The variation widened when supply was estimated relative to disease burden (e.g., ICU beds varied more than 65 -fold from $0.06 / 100$ deaths due to acute illnesses in Kumasi to 4.11/100 in Bogota; ambulance services varied more than 100-fold). Hospital bed per disease burden was associated with gross domestic product (GDP) $\left(R^{2}=0.88, p=0.01\right)$, but ICU supply was not $\left(R^{2}=0.33, p=0.18\right)$. No city provided all requested data, and only two had ICU data. Conclusions: Urban acute care services vary substantially across economic regions, only partially due to differences in GDP. Cities were poor sources of information, which may hinder their future planning.

Keywords Urban population .

Acute care services .

Global burden of disease .

Hospital beds - Intensive care beds . Ambulances

\section{Introduction}

For the first time in history, most of the world's population lives in cities [1], predominantly because of rapid population movement from rural to urban areas in middleincome countries [2]. As these cities rapidly expand, they may fail to invest in infrastructure for housing, transport, sanitation, and healthcare delivery [1]. The United Nations, the World Bank, and many economists state that this failure will persist if left to market forces alone, and therefore recommend government-led needs assessments and coordinated public and public-private investment [3, 4]. Without such action, current estimates suggest that two billion people, or one quarter of the world's population, will be living in urban slums by 2035 [3].

In low-income countries, basic needs such as sanitation and food supply remain paramount. However, for middle-income countries, which represent half the world's population, acute care services, such as ambulance systems, hospitals, emergency departments, and intensive care units (ICUs), are fundamental urban healthcare infrastructure. Indeed, Firth and Ttendo recently argued that a short period of ICU care in limited resource settings is a cost-effective part of the treatment of acute life-threatening conditions that affect millions of lives [5]. However, there are no methods or standards to assess the adequacy of urban acute care services in different settings. In this paper, we report a study of acute care services in seven cities around the world. Our objectives were to generate and compare estimates of the supply of acute care services across cities in diverse regions, and to assess the extent to which the data were readily available to cities for future planning. Results from this study were previously reported in the form of an abstract [6].

\section{Methods}

Study design and sample

We conducted a descriptive cross-sectional study of supply of several measures of acute care services in a convenience sample of seven cities with a population of at least 100,000 from different geographic and economic strata: on the basis of World Bank criteria, two cities from high-income countries (Boston, USA and Paris, France), 
three from upper middle-income countries (Bogota, Colombia; Recife, Brazil; and Liaocheng, China), and two from lower-middle-income countries (Chennai, India and Kumasi, Ghana). We defined supply of acute care services as the number of each service per 100,000 population and per population-adjusted measure of disease burden. With local collaborators, we determined supply from data provided by local and regional authorities and conducted primary data collection when required. We determined the denominators of population and disease burden from existing census data and the Global Burden of Disease (GBD) project [7]. We chose two denominators because neither is ideal. Population data are more likely to be measured similarly across countries and with reasonable accuracy but fail to reflect the varying demand placed on acute care services by variation in disease incidence. Disease burden is thus better theoretically but is measured less accurately.

We obtained approval for the study from the University of Pittsburgh Institutional Review Board (\# PRO11110256) and local institutional officials as required for any prospective collection of facilities data.

\section{Population}

The population count for each city included its urban agglomeration, defined as the population in the city and adjacent suburbs [8]. We obtained the latest urban population estimates (2010-2012) from the United Nations, demographic yearbooks $[9,10]$, and respective national census and local administrative data [11-16].

\section{Acute disease burden}

The GBD project assesses cause-specific mortality to estimate health loss from diseases, injuries, and risk factors for all regions of the world [17]. Extending that method, we chose the number of deaths due to acute illnesses as our standard metric for disease burden. Our goal was not to measure the total burden, but rather to have a measure, proportional to burden, that permits the calculation of population-adjusted rates of supply of acute care services. The advantage of focusing on mortality is that we could rely on the GBD project, the world's largest and most comprehensive effort to measure disease burden. The two limitations are that assignment of cause-specific mortality is prone to error and differences in case-fatality rates across cities confound the assumption that deaths are proportional to disease burden (see "Limitations").

We abstracted data from the 2008 GBD project update [7], which estimates the number of deaths per country in multiple categories of diseases. The 2008 data are the latest available at the required level of granularity. Two investigators (NKJA, SM) independently selected all communicable and non-communicable diseases whose burden would potentially be mitigated by acute care services. Disagreements were resolved by consensus of all study investigators. We selected the following illnesses: respiratory infections (otitis media, lower, and upper respiratory infections), injuries (road traffic accidents, poisoning, falls, fires, drowning, self-inflicted injuries, violence due to war and civil conflicts), and other acute illnesses (tuberculosis, diarrheal diseases, childhoodcluster diseases, meningitis, malaria, tropical-cluster diseases, dengue, Japanese encephalitis, nephritis and nephrosis, cardiovascular and respiratory diseases, maternal conditions, and diabetes mellitus). The sum of deaths across all categories was defined as the number of deaths due to acute illnesses. For each city, we estimated the number of deaths due to acute illnesses as number of deaths due to acute illnesses in the country $\times$ (city population/country population). We performed similar calculations using GBD age categories of $0-14,15-59$, and 60 years and over.

\section{Acute care services supply}

We developed a data collection instrument (see "Appendix") to gather information on the numbers of hospitals, hospital beds, ICU beds, and ambulances available in each city to serve the general population. Our goal was to create standard definitions applicable for all selected cities. After pilot testing and revision, our final instrument used the following definitions. Hospitals (including pediatric hospitals): those with an emergency department and capable of managing acute communityacquired illnesses, including government and private hospitals that provided substantial public access, as adjudicated by local collaborators. Hospital beds: staffed, acute care, non-neonatal beds capable of delivering intravenous fluids, medications, and oxygen. ICU beds: staffed with higher intensity nursing than available on acute care wards and the ability to provide oxygen therapy, pulse oximetry, vasopressors or invasive hemodynamic monitoring (e.g., ability to measure central venous pressure), and invasive mechanical ventilation. Self-defined ICU beds: as defined by the region or hospital, regardless of whether the definition agreed with our standardized definition. Ambulances: vehicles (including those operated by the fire department) that transport acutely ill patients from home to hospitals and vice versa, excluding vehicles that solely transport patients between hospitals.

To obtain data, we identified local collaborators in each city. We circulated data collection instruments via email and held monthly conference calls to provide clarification and updates on the data collection process. Each collaborator collected data between January and September 2012. Collaborators first attempted to obtain 
data from government sources. If data were unavailable, collaborators conducted web searches and contacted other local data sources or individual hospitals, as required. We kept a log of all efforts to collect data.

\section{Analysis}

For each city, we calculated acute care services supply (hospitals, hospital beds, ICU beds, and ambulances) per 100,000 population and per 100 deaths due to acute illnesses. We also calculated disease burden as the total deaths due to all acute illnesses, respiratory infection deaths, and deaths due to injury per 100,000 population. For each disease burden category, we also calculated subtotals by age. We tested using regression statistics for any linear or non-linear relationship between supply of acute care services per 100 deaths and national gross domestic product (GDP) per capita, obtained from the World Bank [18]. Unless otherwise stated, when comparing ICU beds, we used the standardized rather than 'self-defined' count. We enumerated the barriers to data collection identified by our local collaborators. All data management and analyses were conducted using SPSS version 19 (IBM, Armonk NY) and Microsoft Excel 2007 (Microsoft, Redmond WA).

\section{Results}

City characteristics and population

The city populations ranged from 2,035,064 for Kumasi to $11,914,812$ for Paris, with a population density ranging from 671 persons per $\mathrm{km}^{2}$ for Liaocheng to 8,012 persons per $\mathrm{km}^{2}$ for Kumasi (Table 1). The per capita GDP varied 25 -fold, from US\$1,884 in Kumasi to US\$48,442 in Boston.

\section{Deaths due to acute illnesses}

Table 2 shows total and age-based distribution of deaths due to acute illnesses per 100,000 population in the seven cities. As anticipated, there was considerable variation in the death rates. The burden was generally highest in Kumasi (620.5 deaths due to acute illnesses per 100,000 population and 57.8 deaths due to respiratory infections per 100,000 population). Bogota had the smallest burden of deaths due to acute illnesses (288.0 per 100,000 population) but the highest rate of injury deaths ( 93.0 per 100,000 population). Liaocheng had the fewest respiratory infection-related deaths (13.8 per 100,000 population). Adults 60 years old and older had higher deaths due to all acute illnesses and respiratory infection except in Chennai and Kumasi, where the burden of deaths due to respiratory infection was highest in children (0-14 years old).

\section{Acute care services supply}

Table 3 shows the distribution of acute care supply per 100,000 population. For hospital beds, the two cities in high-income countries (Boston and Paris) had the highest supply, while Kumasi had the lowest. All hospital beds in Boston, Paris, Recife, and Liaocheng could deliver intravenous fluids, medications, and oxygen, but not all hospital beds in Bogota, Chennai, and Kumasi were equipped with oxygen. Therefore, although hospital beds varied by a little more than threefold, there was a more than 30-fold variation in the supply of oxygen-capable beds.

Local definitions of ICU beds were often more liberal than the standardized definition. According to the standardized definition, ICU beds comprised 3-9\% of all hospital beds in Boston, Bogota, Chennai, Paris, and Recife. ICU bed supply was somewhat lower in Liaocheng, and very low in Kumasi. ICU beds had a more than 45 -fold variation, from 0.4 per 100,000 population in Kumasi to 18.8 per 100,000 population in Boston. Boston had a very high supply of ambulances compared to all other cities, while Kumasi had the fewest $(>70$-fold variation).

Data on acute care supply per 100 deaths due to acute illnesses are displayed in Table 4. Generally, the variation was higher than population-based data. There was a more than 40-fold difference in the availability of hospital beds with capacity for oxygen. The supply of ICU beds varied from less than 1 to 4 per 100 deaths. The supply of ambulances varied from 0.06 to 6.06 per 100 deaths in Kumasi compared to Boston. The supply of hospital beds per 100 deaths due to acute illnesses had a strong positive correlation with national GDP per capita $(r=0.80$, $p=0.03$ ). However, the relationship between ICU bed supply and national GDP per capita was not statistically significant ( $r=0.57, p=0.18$ ) (Fig. 1). We also fitted a non-linear regression line to the non-linear link between hospital beds and per capita GDP that best explained the association between the variables $\left(R^{2}=0.88, p=0.01\right)$. On the other hand, we did not observe any significant association between ICU beds and GDP by linear $\left(R^{2}=0.33, p=0.18\right)$ or non-linear analysis $\left(R^{2}=0.40\right.$, $p=0.35)$.

Availability and access to data on supply of acute care services

Five cities had a centralized data source for at least some data regarding supply of acute care services. For Chennai 
and Kumasi, all data had to be collected by local investigators directly from acute care institutions (Table 5). No city could provide all the information we sought. For example, information regarding ambulances in Paris required contact with each individual fire station. Similarly, we had to contact each hospital in Recife, Bogota, and Liaocheng to determine the number of ICU beds. The richest data for hospital and ICU beds were available for Boston. However, these data were submitted directly by the hospitals to state and federal government with no obvious oversight by city planners. Availability of ambulance data was highly fragmented in most cities.

\section{Discussion}

We noted three broad findings. First, there was wide variation in the supply of acute care services, such as hospital beds, ICU beds, and ambulances, across the seven cities. That much of the variation correlated with GDP was not surprising. That variation in some aspects of supply, such as ICU care, was not correlated with GDP was surprising, and potentially concerning, especially since the variation was larger when adjusting for burden of disease. Second, not all supply varied widely. For example, several measures of supply were generally similar in both the high- and upper-middle-income cities. Third, much of the data required for the study were not available from urban governments, which was not only challenging for the study, but raises concerns regarding the ability of cities to plan for the future.
Variation in the provision of healthcare services is widely reported, both within and across countries. Many countries have large-scale efforts underway to minimize unwanted variation, both to ensure adequate access to vulnerable populations and to avoid excess use of potentially expensive resources. Key to such initiatives is a method to define optimal supply targets. Even within high-income countries, there is no clear agreement on optimal supply of acute care services. For example, we previously reported eightfold variation in ICU beds per population across eight high-income countries, ranging from 3 to 24 beds per 100,000 [19]. Where 'optimal' lies in this range is unclear but it is likely somewhere in the middle: data from the UK, which had three ICU beds per 100,000 , suggest ICU supply is too low [20], whereas the USA, which had a high provision, is struggling to control unsustainably high costs. The relationship between per capita GDP and hospital beds in our sample was not linear, suggesting there may be a point, or asymptote, beyond which greater per capita GDP does not fuel greater supply. Given the small sample, we would urge caution in over-interpreting this relationship until it is validated in a larger study. Whether this relationship suggests that the asymptote represents the optimal supply is also hard to interpret because we do not know whether the relationship is causal. And, of course, as previously noted, there was no relationship between ICU supply and disease burden.

Previous ICU-based studies from upper-middle-income countries have often reported higher than expected mortality when compared to cohorts from high-income countries. One possible explanation was that upper-middle-income

Table 1 Descriptive characteristics of the seven cities

\begin{tabular}{|c|c|c|c|c|c|c|c|}
\hline \multirow[t]{2}{*}{ Characteristic } & \multicolumn{7}{|l|}{ City } \\
\hline & Boston & Paris & Recife & Bogota & Liaocheng & Chennai & Kumasi \\
\hline Country & USA & France & Brazil & Colombia & China & India & Ghana \\
\hline Income region & High & High & Upper-middle & Upper-middle & Upper-middle & Lower-middle & Lower-middle \\
\hline Population & $5,576,108^{b}$ & $11,914,812^{\mathrm{c}}$ & $3,743,854^{\mathrm{d}}$ & $8,759,400^{\mathrm{e}}$ & $5,849,100^{\mathrm{f}}$ & $8,784,000^{\mathrm{g}}$ & $2,035,064^{\mathrm{h}}$ \\
\hline Area $\left(\mathrm{km}^{2}\right)$ & 4,595 & 2,845 & 2,768 & 1,587 & 8,715 & 1,189 & 254 \\
\hline Density (persons $/ \mathrm{km}^{2}$ ) & 1,193 & 4,171 & 1,069 & 4,705 & 671 & 7,388 & 8,012 \\
\hline GDP per capita (2011 US\$) ${ }^{a}$ & 48,442 & 35,194 & 11,719 & 10,103 & 8,442 & 3,650 & 1,884 \\
\hline Healthcare access & $\begin{array}{l}\text { No universal } \\
\text { coverage }\end{array}$ & $\begin{array}{l}\text { Universal } \\
\text { coverage }\end{array}$ & $\begin{array}{l}\text { Universal } \\
\text { coverage }\end{array}$ & $\begin{array}{l}\text { Universal } \\
\text { coverage }\end{array}$ & $\begin{array}{l}\text { Universal } \\
\text { coverage }\end{array}$ & $\begin{array}{l}\text { No universal } \\
\text { coverage }\end{array}$ & $\begin{array}{l}\text { Universal } \\
\text { coverage }\end{array}$ \\
\hline
\end{tabular}

\footnotetext{
a World Bank, International Comparison Program Database, ${ }^{\mathrm{f}}$ The state of China's cities-UN habitat report (2010/2011), http:// http://data.worldbank.org/indicator/NY.GDP.PCAP.PP.CD. These are national level estimates, not urban agglomeration specific GDP

b http://quickfacts.census.gov/qfd/states/25/25021.html (2012)

c National Institute of Statistics and Economic Studies-France, http://www.insee.fr/ (2012)

d Instituto Brasileiro de Geografia e Estatística (IBGE) 2012, http:// www.metadados.ibge.gov.br/detalhePesquisa.aspx?cod=CD (2012) www.unhabitat.org/pmss/listItemDetails.aspx?publicationID $=3012$ $\mathrm{g}$ Population Division of the Department of Economic and Social Affairs of the United Nations Secretariat, World Population Prospects: The 2010 revision and world urbanization prospects: The 2011 revision, http://esa.un.org/unpd/wup/unup/p2k0data.asp

h Ghana Statistical Service 2010, http://www.statsghana.gov.gh/ contact_us.html
}

html (2011) 
Table 2 Deaths due to acute illnesses in the seven cities per 100,000 population stratified by age

\begin{tabular}{|c|c|c|c|c|c|c|c|}
\hline & Boston & Paris & Recife & Bogota & Liaocheng & Chennai & Kumasi \\
\hline \multicolumn{8}{|c|}{ All deaths due to acute illnesses } \\
\hline Total & 458.73 & 377.11 & 404.94 & 288.00 & 503.29 & 611.73 & 620.54 \\
\hline $0-14$ & 3.23 & 1.18 & 10.50 & 16.00 & 14.47 & 97.56 & 146.16 \\
\hline $15-59$ & 86.71 & 43.96 & 131.52 & 119.53 & 98.49 & 182.53 & 224.95 \\
\hline$\geq 60$ & 368.79 & 331.97 & 262.92 & 152.47 & 390.33 & 331.64 & 249.43 \\
\hline \multicolumn{8}{|c|}{ Respiratory infection deaths ${ }^{a}$} \\
\hline Total & 18.45 & 21.84 & 31.92 & 16.03 & 13.79 & 57.58 & 57.80 \\
\hline $0-14$ & 0.20 & 0.06 & 2.41 & 5.47 & 4.88 & 34.69 & 31.85 \\
\hline $15-59$ & 1.53 & 0.98 & 5.58 & 2.19 & 1.13 & 3.88 & 10.64 \\
\hline$\geq 60$ & 16.72 & 20.80 & 23.93 & 8.37 & 7.78 & 19.01 & 15.31 \\
\hline \multicolumn{8}{|c|}{ Injury deaths ${ }^{b}$} \\
\hline Total & 59.93 & 55.70 & 75.84 & 92.93 & 70.32 & 82.98 & 71.01 \\
\hline $0-14$ & 2.20 & 0.70 & 4.13 & 5.86 & 6.78 & 10.78 & 11.01 \\
\hline $15-59$ & 39.33 & 22.11 & 59.41 & 78.20 & 40.45 & 51.00 & 49.68 \\
\hline$\geq 60$ & 18.40 & 32.89 & 12.30 & 8.87 & 23.08 & 21.20 & 10.32 \\
\hline \multicolumn{8}{|c|}{ Acute deaths due to other acute illnesses ${ }^{\mathrm{c}}$} \\
\hline Total & 380.35 & 299.56 & 297.18 & 179.04 & 419.17 & 471.16 & 491.73 \\
\hline $0-14$ & 0.85 & 0.41 & 3.95 & 4.67 & 2.80 & 52.09 & 103.29 \\
\hline $15-59$ & 45.84 & 20.88 & 66.54 & 39.15 & 56.91 & 127.64 & 164.63 \\
\hline$\geq 60$ & 333.66 & 278.27 & 226.69 & 135.22 & 359.46 & 291.43 & 223.81 \\
\hline
\end{tabular}

Estimated deaths extrapolated from Global Burden of Disease ${ }^{c}$ Tuberculosis, diarrheal diseases, childhood-cluster diseases, project data for the entire country

a Otitis media, lower and upper respiratory infections

b Road traffic accidents, poisoning, falls, fires, drowning, self- diseases, maternal illnesses, and diabetes mellitus

inflicted injuries, violence, war, and civil conflicts meningitis, malaria, tropical-cluster diseases, dengue, Japanese encephalitis, nephritis and nephrosis, cardiovascular and respiratory

inficted injuries, violence, wa

Table 3 Acute care supply in the seven cities per 100,000 population

\begin{tabular}{|c|c|c|c|c|c|c|c|}
\hline Acute care service & Boston & Paris & Recife & Bogota & Liaocheng & Chennai $^{\mathrm{a}}$ & Kumasi \\
\hline Hospitals ${ }^{b}$ & 1.47 & 0.55 & 1.28 & 0.67 & 0.19 & 1.05 & 0.44 \\
\hline $\begin{array}{l}\text { Hospital beds }{ }^{c} \text { (capacity for IV } \\
\text { fluids and medications) }\end{array}$ & 241.57 & 233.81 & 187.48 & 128.74 & 128.97 & 166.84 & 72.43 \\
\hline Hospital beds ${ }^{\mathrm{d}}$ (with oxygen capacity) & 241.57 & 233.81 & 187.48 & 88.56 & 117.90 & 153.38 & 7.27 \\
\hline ICU beds $\mathrm{e}^{\mathrm{e}}$ & 18.85 & 8.38 & 14.90 & 11.42 & 2.80 & 4.93 & 0.39 \\
\hline Self-defined ICU beds ${ }^{\mathrm{f}}$ & 18.85 & 19.06 & 14.90 & 14.59 & 6.29 & 12.84 & 0.69 \\
\hline Ambulances ${ }^{g}$ & 27.80 & 4.20 & 2.03 & 3.96 & 0.77 & 1.76 & 0.39 \\
\hline
\end{tabular}

Includes infrastructure from government and private healthcare ${ }^{\mathrm{e}}$ Number of ICU beds with the capacity to deliver oxygen therapy, facilities with substantial portion of public access

${ }^{a}$ Data represents $73 \%$ hospitals in Chennai. The actual estimates will be higher

b Hospitals, with an emergency department, that are part of a system capable of managing acute community acquired conditions, including pediatric hospitals

c Number of staffed and available acute care hospital beds with the capacity to deliver IV fluids and medications (for patients admitted from the emergency department)

d Number of staffed and available acute care hospital beds with the capacity to deliver oxygen by any delivery system (for patients admitted from the emergency department)

countries had far fewer ICU beds and therefore restricted ICU admission to much sicker patients. Our data would suggest this explanation seems less likely as the number of ICU beds per capita for upper-middle-income countries fell within the range of high-income countries, and thus raises the importance of determining whether access is equitable or whether the quality of care prior to or during the ICU pulse oximetry, vasopressors, or invasive hemodynamic monitoring (e.g., ability to measure central venous pressure), and invasive mechanical ventilation, and with higher intensity nursing than available on acute care wards

${ }^{\mathrm{f}}$ Number of beds classified as ICU beds by the region or the hospital

$\mathrm{g}$ Vehicles providing services of transporting patients from home to hospital and between hospitals and not used exclusively for transfer between hospitals

admission is adequate. Given that ICU facilities are expensive to build and maintain, it would seem imperative to ensure that they are used as wisely as possible. The cities from lower-middle-income countries had a far lower supply of acute care services, and thus these cities should arguably first focus on how and whether to build the volume of these services. 
Table 4 Acute care supply per 100 deaths due to acute illnesses

\begin{tabular}{|c|c|c|c|c|c|c|c|}
\hline Acute care service & Boston & Paris & Recife & Bogota & Liaocheng & Chennai $^{\mathrm{a}}$ & Kumasi \\
\hline Hospitals ${ }^{b}$ & 0.32 & 0.15 & 0.32 & 0.23 & 0.04 & 0.20 & 0.07 \\
\hline $\begin{array}{l}\text { Hospital beds }{ }^{c} \text { (capacity for IV } \\
\text { fluids and medications) }\end{array}$ & 52.66 & 62.00 & 46.30 & 44.70 & 23.43 & 27.27 & 11.67 \\
\hline Hospital beds ${ }^{\mathrm{d}}$ (with oxygen capacity) & 52.66 & 62.00 & 46.30 & 30.75 & 23.43 & 25.07 & 1.17 \\
\hline ICU beds ${ }^{\mathrm{e}}$ & 4.11 & 2.22 & 3.68 & 3.96 & 0.56 & 0.81 & 0.06 \\
\hline Self-defined ICU beds ${ }^{\mathrm{f}}$ & 4.11 & 5.05 & 3.68 & 5.07 & 1.25 & 2.10 & 0.11 \\
\hline Ambulances $^{\mathrm{g}}$ & 6.06 & 1.11 & 0.50 & 1.38 & 0.15 & 0.29 & 0.06 \\
\hline
\end{tabular}

Includes infrastructure from government and private healthcare facilities with substantial portion of public access

a Data represents $73 \%$ hospitals in Chennai. The actual estimates will be higher

b Hospitals, with an emergency department, that are part of a system capable of managing acute community-acquired conditions, including pediatric hospitals

c Number of staffed and available acute care hospital beds with the capacity to deliver IV fluids and medications (for patients admitted from the emergency department)

d Number of staffed and available acute care hospital beds with the capacity to deliver oxygen by any delivery system (for patients admitted from the emergency department)

As urban populations expand in middle-income countries, access to acute care supply may further deteriorate without prospective planning. Planning, however, will be impossible in the absence of data. Unfortunately, the cities from lower-middle-income countries, which currently have the poorest acute care services supply and are facing the largest population growth projections, were the least likely to provide data. While it is possible that the cities had the data and were unwilling to share, this scenario is unlikely for the following reasons: first, when we could not identify a city source or obtain information from a city source, we performed an extensive online search for urban government or private city websites with information on acute care supply. There was no instance when a city did not provide data, and yet the data were available online. Second, if the city did not have the data, our local investigators collected the data directly. During this process, no local sites told us that they already reported the data to the city.

Given that there are no well-recognized metrics for acute care services supply, it is not surprising that cities lack comprehensive data. This lapse is shortsighted given the importance of planning for investment in infrastructure, of which healthcare is an essential pillar. In contrast, data do exist for the supply and demand of other essential urban infrastructures, such as housing, sanitation, and transportation [21-23].

A second threat to effective urban planning for acute care services supply is that healthcare is often not under the direct control of local government, in contrast to other key infrastructure. Thus, cities have to engage in cooperative planning and governance with national or regional governments and with private third parties. Public-private partnerships have been developed to tackle certain specific
${ }^{\mathrm{e}}$ Number of ICU beds with the capacity to deliver oxygen therapy, pulse oximetry, vasopressors, or invasive hemodynamic monitoring (e.g., ability to measure central venous pressure), and invasive mechanical ventilation, and with higher intensity nursing than available on acute care wards

${ }^{f}$ Number of beds classified as ICU beds by the region or the hospital

g Vehicles providing services of transporting patients from home to hospital and between hospitals and not used exclusively for transfer between hospitals

diseases, such as prevention programs for HIV/AIDS and tuberculosis [24]. However, whether there could be lessons learned for urban acute care services supply is less clear.

\section{Limitations}

There are several important limitations. First, this study represents an initial attempt to measure urban acute care supply and thus focused on a small convenience sample. The chosen cities may not be representative of their economic regions, and thus we urge caution in extrapolating our findings. Second, there are no standardized approaches for the measurement of acute care services. We therefore chose a set of simple counts of different structural elements (e.g., the number of ambulances or full-service ICU beds). We attempted to standardize their definitions to ensure reliability. However, we cannot comment, for example, on whether the care provided in one ICU is of similar quality or intensity to that provided in another. Also, some services for which we collected data may be able to flux rapidly in response to patients' needs, such as the number of hospital beds equipped with cylinder-supplied oxygen. Third, even though we standardized definitions of data elements, the method of data collection (e.g., use of existing centralized data vs. manual data collection) varied depending on availability. Although we attempted to verify all data, it is possible that the different methods biased our results.

We relied on GBD project data for our measure of disease burden. GBD also suffers from variable data collection methodologies across regions and relies heavily on cause-of-death data, which are prone to error and capture only some aspects of disease burden. Differences in the 


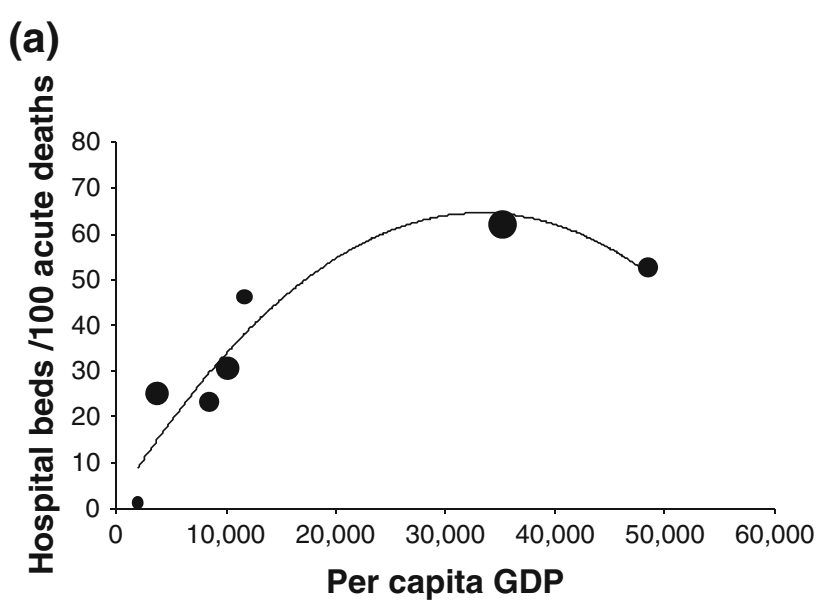

(b)

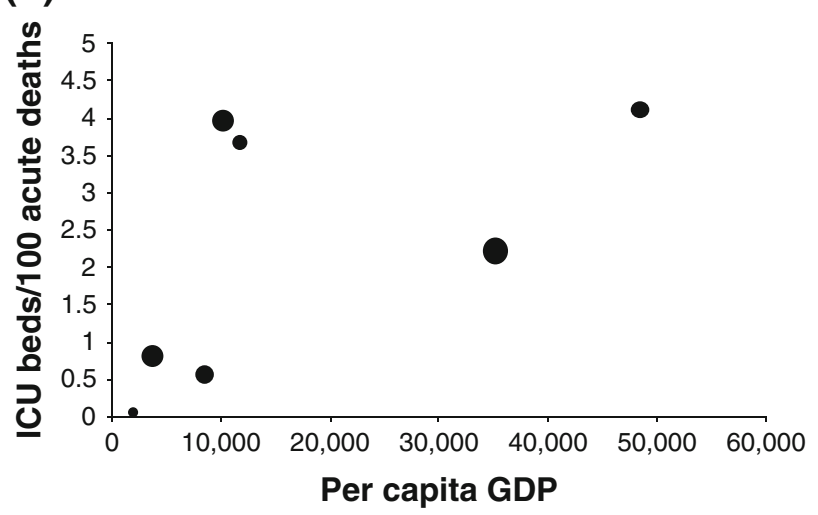

Fig. 1 Per capita GDP, acute care supply, and population for seven cities. Data points on the bubble chart represent cities' national GDP per capita in 2011 US\$ (based on purchasing power parity) and ratios of acute care supply to 100 deaths due to acute illnesses. The size of the bubble represents city population. Relationship between national GDP per capita and supply of a hospital beds or b ICU beds per 100 deaths due to acute illnesses. Hospital bed supply, as shown by the best-fitting regression curve, was highly associated with per capita GDP $\left(R^{2}=0.88, p=0.01\right)$, whereas ICU supply was not $\left(R^{2}=0.33, p=0.18\right)$

mortality rate across cities may have led to inaccuracy in projecting the overall burden of a given disease. Furthermore, we selected only those deaths attributed to diseases we considered likely to require acute care. Our selection criteria were based on expert opinion, and are somewhat arbitrary, although we note that others recently proposed a similar approach [25]. Differences in the age distributions in both of the underlying populations and of the incidence of acute illnesses can have a large effect on estimates of supply. Although we adjusted for age where possible, we note that the age categories available from GBD and census data are broad and finer age categorization may have yielded different estimates. We expressed our counts as overall ratios for the entire urban region. Our findings could be distorted by differences in how urban regions are defined and there could be wide variation in access and supply within any given city. Differences in the ratio of mortality rates between rural and urban areas could also affect our estimates of disease burden.

\section{Implications and future research}

Previous research on supply of acute care services has generally centered on high-income countries and has not focused on the entire spectrum of acute care services supply, from ambulances to ICU beds. Without data, accurate planning for investment in acute care cannot occur. Our results may aid policy makers and researchers regarding decisions on appropriate investments in infrastructure required to meet the acute disease burden in cities, the now dominant location of human habitation. Comparison across cities using standardized data collection tools for acute care supply and estimates of disease burden would help to determine the optimal supply of acute care services. Standardized definitions of the composition, training, and competencies of the workforce providing acute care will further enhance this effort.

Conflicts of interest The authors declare no conflicts of interest.

Open Access This article is distributed under the terms of the Creative Commons Attribution Noncommercial License which permits any noncommercial use, distribution, and reproduction in any medium, provided the original author(s) and the source are credited.

Table 5 Access to information on supply of acute care services

\begin{tabular}{|c|c|c|c|c|c|c|c|}
\hline Level of data and planning & Boston & Paris & Recife & Bogota & Liaocheng & Chennai & Kumasi \\
\hline Centralized data source $^{\mathrm{a}}$ & Yes & Yes & Yes & Yes & Yes & No & No \\
\hline $\begin{array}{l}\text { All data obtained from } \\
\text { the centralized source }\end{array}$ & No & No & No & No & No & No & No \\
\hline $\begin{array}{l}\text { Identifiable urban authority } \\
\text { for acute care services }\end{array}$ & Yes & Yes & Yes & Yes & Yes & Yes & Yes \\
\hline City provided data & $\mathrm{No}^{\mathrm{b}}$ & No & No & No & No & No & No \\
\hline Some or all data collected de novo & No & Yes & Yes & Yes & No & Yes & Yes \\
\hline
\end{tabular}

Data related to, for example, access to information on number of ${ }^{b}$ Data obtained from Centers for Medicare and Medicaid Service's hospitals and number of hospital beds

${ }^{\text {a }}$ For example, national or urban healthcare administrative data Healthcare Cost Report Information System and Massachusetts Office of Emergency Medical Services 


\section{Appendix}

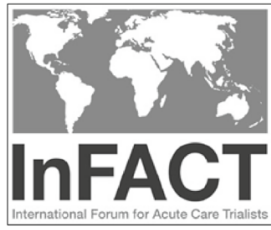

\section{Accounting of Cities' Capacity for Emergency Services}

Your city is:

Your city population is:

(Source: World Urbanization Prospects; 2011Revision)

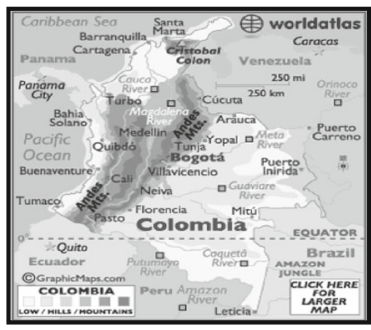

Please answer questions 1 to 3 below. For each response, please provide the source of this data by entering a reference number (e.g. 1, 2, 3 etc.) in the relevant place and then completing the information of this source in the table at the end of this questionnaire.
1. Is the city population stated above correct?
Yes $\square \quad$ No $\square$
If No, please provide correct city population
Source of data reference:

2. In the table overleaf, please complete the number of Hospitals, Hospital beds and ICU beds, relative to the city population described above (referring to the following listed definitions). Definitions:

a. Hospital - Hospitals, with an emergency department, that are part of a system capable of managing acute community acquired conditions, including pediatric hospitals

b. Hospital beds (with capacity for IV fluids and medications) - Number of staffed and available acute care hospital beds with the capacity to deliver IV fluids and medications (for patients admitted from the emergency department).

b should include count of: $\mathbf{c}+\mathbf{d}+\mathbf{e}+\mathbf{f}$

c should include count of $\mathbf{d}+\mathbf{e}+\mathbf{f}$

c. Hospital beds (with capacity for oxygen) - Number of staffed and available acute care hospital beds with the capacity to deliver oxygen by any delivery system (for patients admitted from the emergency department).

d. ICU beds (self-defined) - Number of beds classified as ICU beds by the region or the hospital

d should include count of:

$\mathbf{e}+\mathbf{f}$

e. ICU beds (with/without capacity for invasive mechanical ventilation) - Number of ICU beds that have the capacity to deliver oxygen, pulse oximetry, vasopressors or invasive hemodynamic monitoring (e.g. ability to measure central venous pressure) and with higher intensity nursing than available on acute care wards.

f. ICU beds (with capacity for invasive mechanical ventilation) - As per e plus capacity to deliver invasive mechanical ventilation.

\begin{tabular}{|c|c|c|c|c|c|c|c|c|c|c|c|c|}
\hline \multirow[t]{2}{*}{ Hospital type } & \multicolumn{2}{|c|}{ Hospitals ${ }^{a}$} & \multicolumn{2}{|c|}{$\begin{array}{l}\text { Hospital beds }{ }^{\mathbf{b}} \\
\text { (with capacity for } \\
\text { IV fluids and } \\
\text { medications) }\end{array}$} & \multicolumn{2}{|c|}{$\begin{array}{l}\text { Hospital beds }{ }^{\mathbf{c}} \\
\text { (with capacity for } \\
\text { oxygen) }\end{array}$} & \multicolumn{2}{|c|}{$\begin{array}{l}\text { ICU beds }{ }^{\mathbf{d}} \\
\text { (self-defined) }\end{array}$} & \multicolumn{2}{|c|}{$\begin{array}{c}\text { ICU beds }^{\mathrm{e}} \\
\text { (with/without capacity } \\
\text { for invasive mechanical } \\
\text { ventilation) }\end{array}$} & \multicolumn{2}{|c|}{$\begin{array}{c}\text { ICU beds } \mathbf{s}^{\mathbf{f}} \\
\text { (with capacity for } \\
\text { invasive mechanical } \\
\text { ventilation) }\end{array}$} \\
\hline & Number & Source & Number & Source & Number & Source & Number & Source & Number & Source & Number & Source \\
\hline $\begin{array}{l}\text { Government funded with full public } \\
\text { access (directly supported by } \\
\text { local/regional government with } \\
\text { contracts to provide care) }\end{array}$ & & & & & & & & & & & & \\
\hline $\begin{array}{l}\text { Privately run but providing a } \\
\text { substantial portion of public access }\end{array}$ & & & & & & & & & & & & \\
\hline $\begin{array}{l}\text { Privately run with some public } \\
\text { access }\end{array}$ & & & & & & & & & & & & \\
\hline $\begin{array}{l}\text { Specialty privately run hospital } \\
\text { with no or rare capacity to provide } \\
\text { public care }\end{array}$ & & & & & & & & & & & & \\
\hline $\begin{array}{l}\text { Other } \\
\text { Please specify: }\end{array}$ & & & & & & & & & & & & \\
\hline
\end{tabular}

3. Please state the number of ambulances operating in the city available all or most of the time to respond to emergencies in public places and private homes of the city population (includes air ambulances; does not include ambulances used solely or mostly for intra-hospital transfer)

Number of ambulances:

Source of data reference: 


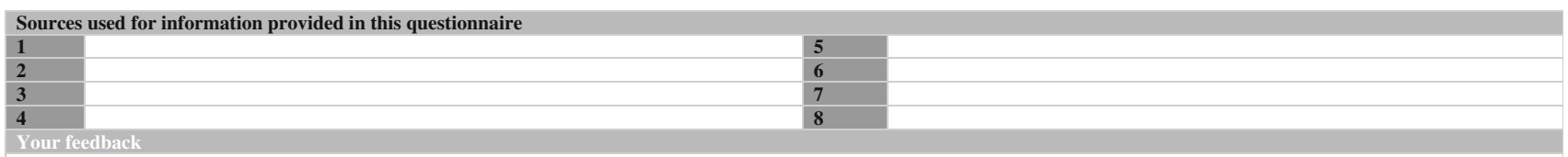

One of the goals of this pilot is to work out the utility of this questionnaire. We would be grateful for your feedback on the following:

Please comment on things that you found difficult when completing this questionnaire.

Would a worksheet have been helpful?

Yes $\square \quad$ No $\square$

Comments:

In order to help us develop a better instrument - if you have additional data sheets you used to generate this information, and are willing to share these, please attach these with your completed questionnaire.

How did you collect the data (e.g. administrative dataset versus data from each individual hospital, etc.)?

We would like to contact you to discuss completion of this questionnaire. Please provide your contact details.

Name:

Telephone number:

\section{References}

1. United Nations Population Fund (2007)

Urbanization: a majority in cities.

http://www.unfpa.org/pds/

urbanization.htm. Accessed 10 July 2012

2. United Nations Population Fund (2008)

State of world population 2007: unleashing the potential of urban growth. http://www.unfpa.org/ swp/2007/presskit/pdf/sowp2007_ eng.pdf. Accessed 10 July 2012

3. Annez PC, Linn JF (2010) Agenda for research on urbanization in developing countries: a summary of findings from a scoping exercise. http://elibrary. worldbank.org/content/workingpaper/ 10.1596/1813-9450-5476. Accessed 8 Aug 2012

4. United Nations Department of Economic and Social Affairs Population Division (2011) Population distribution, urbanization, internal migration, and development: an international perspective. http://www.un.org/esa/population/ publications/PopDistribUrbanization/ PopulationDistributionUrbanization.pdf Accessed 8 Aug 2012

5. Firth P, Ttendo S (2012) Intensive care in low-income countries-a critical need. N Engl J Med 367:1974-1976
6. Murthy S, Austin S, Wunsch H, Adhikari NKJ, Karir V, Rowan K, Jacob ST, Salluh J, Bozza F, Du B, An Y, Lee B, Wu F, Oppong C, Venkataraman R, Velayutham V, Angus DC (2013) Variation in acute care burden and supply across diverse urban settings. Crit Care 17(Suppl 2):P489

7. World Health Organization (2008) The global burden of disease: 2004 update. http://www.who.int/healthinfo/ global_burden_disease/ GBD_report_2004update_full.pdf. Accessed 4 June 2012

8. United Nations Department of Economic and Social Affairs Population Division (2012) World urbanization prospects: the 2011 revision. http://esa.un.org/unup/ Documentation/WUP_glossary.htm. Accessed 12 Nov 2012

9. United Nations Department of Economic and Social Affairs Population Division (2010) World urbanization prospects: the 2011 revision. http://esa.un.org/unup/ unup/index_panel2.html. Accessed 14 Sept 2013
10. United Nations Department of Economic and Social Affairs Population Division (2011) 2009-2010 UN demographic yearbook. http:// unstats.un.org/unsd/demographic/ products/dyb/dybsets/2009-2010.pdf. Accessed 14 Sept 2013

11. US Census Bureau (2012) State and county quickfacts. http://quickfacts.census.gov/qfd/states/ 25000.html. Accessed 14 Sept 2013

12. National Institute of Statistics and Economic Studies (INSEE) (2012) The population census. http://www.insee.fr/. Accessed 14 Sept 2013

13. City population (2013) Colombia. http://www.citypopulation.de/ Colombia.html. Accessed 17 Sept 2013

14. Brazilian Institute of Geography and Statistics (IBGE) (2012) Population estimates. http://www.ibge.gov.br/ english/estatistica/populacao/ estimativa2012/estimativa_dou.shtm. Accessed 14 Sept 2013

15. Ghana Statistical Services. Social and Demographic Statistics (2010) http://www.statsghana.gov.gh/ contact_us.html. Accessed 14 Dec 2011 
16. The China Science Center of International Eurasian Academy of Sciences China Association of Mayors UN Habitat (2010) The state of China's cities 2010/2011. Better city, better life. http://www.unhabitat.org/pmss/ listItemDetails.aspx? publicationID= 3012. Accessed 10 July 2013

17. World Health Organization (2013) Global burden of disease (GBD) http://www.who.int/healthinfo/ global_burden_disease/en/. Accessed 10 July 2013

18. The World Bank (2013). GDP per capita, PPP (current international \$). http://data.worldbank.org/indicator/ NY.GDP.PCAP.PP.CD. Accessed 11 Mar 2013

19. Wunsch H, Angus DC, Harrison DA, Collange O, Fowler R, Hoste EA, de Keizer NF, Kersten A, Linde-Zwirble WT, Sandiumenge A, Rowan KM (2008) Variation in critical care services across North America and Western Europe. Crit Care Med 36:2787-2793
20. Goldfrad C, Rowan K (2000) Consequences of discharges from intensive care at night. Lancet 355:1138-1142

21. The International Bank for Reconstruction and Development/The World Bank (2002) Cities on the move. A World Bank urban transport strategy review. http://siteresources.worldbank. org/INTURBANTRANSPORT/ Resources/cities_on_the_move.pdf. Accessed 10 July 2013

22. United Nations Human Settlements Programme (UN-Habitat) (2011) Planning sustainable cities. http://www.unhabitat.org/downloads/ docs/GRHS2009/GRHS.2009.pdf. Accessed 10 July 2013

23. World Health Organization and UNICEF (2013) Progress on sanitation and drinking-water-2013 update. http://apps.who.int/iris/bitstream/ 10665/81245/1/9789241505390 eng.pdf. Accessed 10 July 2013
24. World Health Organization (2009) Investing in our common future. http://www.who.int/pmnch/activities/ jointactionplan/100922_2_investing.pdf. Accessed 10 July 2013

25. Hsiao M, Morris SK, Malhotra A, Suraweera W, Jha P (2013) Timecritical mortality conditions in lowincome and middle-income countries. Lancet 381:993-994 